\title{
An Exploration of the Methodological Flaws for Assessing Fibre Intake Among Canadians
}

\author{
Michelle R. ASBURY* 1 \\ 1 PhD Candidate, University of Toronto, Canada \\ *Auteur(e) correspondant | Corresponding author : michelle.asbury@mail.utoronto.ca
}

\begin{abstract}
:
According to the 2004 Canadian Community Health Survey-Nutrition, the majority of Canadians are consuming fibre below the adequate intake (AI) level. Although an intervention by Health Canada to improve fibre intakes may seem appropriate, there is insufficient evidence to warrant an intervention given the methodological flaws for assessing fibre intakes in the Canadian population. This paper explores these limitations by reviewing how the AI for fibre was developed, by examining how fibre intakes are assessed by the 2004 Canadian Community Health Survey-Nutrition, and by outlining the limitations of using an AI to draw conclusions about fibre inadequacy. Recognizing the pitfalls of this methodology is the first step to improving the assessment of fibre intakes in Canada, which is needed before any intervention by Health Canada is implemented.
\end{abstract}

Keywords:

Résumé :

(traduction)

Fibre, Canadian Community Health Survey, dietary assessment, adequate intake, nutrition

Selon l'Enquête sur la santé dans les collectivités canadiennes-Nutrition menée en 2004, la plupart des Canadiens consomment moins de fibres que l'apport suffisant (AS). Même si une intervention de Santé Canada visant à augmenter l'apport en fibres peut sembler appropriée, il n'existe pas suffisamment de preuves pour en justifier une, compte tenu des lacunes méthodologiques liées à l'évaluation de l'apport en fibres chez les Canadiens. Cette étude se penche sur ces lacunes en examinant la manière dont l'AS en fibres a été déterminé et dont l'apport en fibres a été évalué dans l'Enquête sur la santé dans les collectivités canadiennes-Nutrition menée en 2004, ainsi qu'en soulignant les limites de l'utilisation de l'AS pour tirer des conclusions sur l'insuffisance en fibres. Reconnaitre les lacunes de la méthodologie est la première étape à suivre pour améliorer l'évaluation de l'apport en fibres au Canada, avant toute intervention de Santé Canada.

fibres, Enquête sur la santé dans les collectivités canadiennes, évaluation de l'alimentation, apport suffisant, nutrition 
The Canadian Community Health Survey (CCHS)-Nutrition from 2004 shows that most Canadians are consuming fibre below the adequate intake (AI) level (Health Canada \& Statistics Canada, 2004). Although results from the most recent CCHS-Nutrition in 2015 will allow for an assessment of how fibre intakes have changed in the Canadian population since 2004, there is currently insufficient evidence for Health Canada to implement an intervention strategy to improve the fibre intake of Canadians, given the methodological flaws for assessing fibre intakes and determining fibre inadequacy in the Canadian population. This paper will explore these issues by outlining the limitations to how the fibre AIs were established, highlighting the shortcomings of measuring fibre intake among Canadians, and exploring the challenges of using an AI to draw conclusions about fibre inadequacy in the Canadian population.

\section{Establishing Dietary Requirements for Indi- vidual Nutrients}

When establishing dietary reference intakes for individual nutrients, estimated average requirements (EAR) are ideal, since they are based on a requirement distribution for that given nutrient and its relationship with indicators of adequacy (e.g., prevention of a specific disease, measured biomarkers, or protection against deficiency) (Institute of Medicine, 2006). In cases where insufficient data exists, or a requirement distribution cannot be generated, an $\mathrm{AI}$ is established as an alternative to an EAR. Adequate intakes are based on the observed or estimated intake of a given nutrient in a healthy population, which can also take into account the level of nutrient intake that is associated with preventing a specific disease (Institute of Medicine, 2006).

\section{How the Adequate Intake Level for Fibre was Developed}

Fibre is a non-essential nutrient with no known level of deficiency or developed biomarkers, thereby resulting in an established AI instead of an EAR (Institute of Medicine, 2006). The AIs for fibre were determined using coronary heart disease (CHD) as the disease endpoint, despite its associations with health benefits such as normalizing blood glucose and lipids, and improving laxation (Institute of Medicine, 2005). The selection of CHD as the disease endpoint was based on three large, epidemiological studies of adult men and women that showed a significant reduction of CHD with higher quintiles of fibre consumption

(Pietinen et al., 1996; Rimm et al., 1996; Wolk et al., 1999). A fibre intake of $14 \mathrm{~g} / 1000 \mathrm{kcal}$ was recommended to protect against CHD, as this was the median fibre intake among individuals with the highest quintile of fibre consumption and subsequently lowest risk of CHD across the three epidemiological studies. The AIs for fibre were then determined for each age and sex group by multiplying $14 \mathrm{~g} / 1000 \mathrm{kcal}$ by median energy intakes established by the Continuing Survey of Food Intakes by Individuals (CSFII) (Institute of Medicine, 2005, 2006).

\section{Limitations to how Adequate Intakes for Fibre were Determined}

Unfortunately, there are numerous issues surrounding how the AIs for fibre were established, which stem from limitations in the epidemiological studies used to calculate the AIs. First, studies used to develop dietary reference intakes should examine healthy populations; however, one of the studies used to calculate the fibre AI only included men who smoke $\geq 5$ cigarettes/day (Pietinen et al., 1996; The ATBC Cancer Prevention Study Group, 1994). Furthermore, dietary data for these studies was collected between 1984 and 1993, and none of the cohorts were from Canada, making it questionable whether these epidemiological studies, upon which the AIs for fibre were determined, are generalizable to today's population of healthy Canadians. Secondly, the Institute of Medicine defines the AI as total fibre which is the combination of both dietary (i.e., naturally found in plants) and functional fibre (i.e., isolated or synthesized fibres with known health benefits in humans) (Institute of Medicine, 2006). However, the three studies used to establish the AIs only examined dietary fibres; it is unclear whether functional fibres protect against CHD like dietary fibres, despite their inclusion in the AI definition.

In addition to the issues from the epidemiological studies used to calculate the fibre AIs, there are also limitations in how the AIs were calculated for each age and sex group. First, AIs for children (1-8 years) and adolescents (9-18 years) are extrapolated from older adults to protect against CHD. Since CHD primarily affects individuals $>45$ years (Benjamin et al., 2019), this disease endpoint is not an appropriate outcome measure for younger individuals. Secondly, the CSFII survey was conducted in the US in 1994-6 and 1998 (U.S. Department of Agriculture, Agricultural Research Service, Beltsville Human Nutrition Research Center, \& Food Surveys Research Group, 2016). Given the decline in energy intakes over the last decade (Garriguet, 2018), and the inherent issues surrounding misreporting of energy intakes (Garriguet, 2018; Hébert et al., 2014), it is likely the CSFII does not accurately reflect the energy intake of Canadians today.

Given these methodological issues from the epidemiological studies used to generate the AIs and the calculation of AIs for each age and sex group, the current AIs for fibre are arguably ungeneralizable to all ages of healthy Canadians today. The use of recent, nationally-representative data of fibre and energy intakes from healthy Canadians, and more appropriate disease endpoints for younger individuals, would greatly improve the AIs for fibre.

\section{Limitations to Assessing Fibre Intake in the Canadian Population}

Similar shortcomings should be highlighted in how fibre intakes were assessed in the Canadian population from the 2004 CCHS-Nutrition. First, fibre intakes were assessed only from food sources, not supplements (Health Canada \& Statistics Canada, 2004). As such, the fibre intakes meas- 
ured in CCHS-Nutrition 2004 only reflect dietary fibre, and not functional fibre, thereby underestimating true fibre consumption in the Canadian population. In addition, the CCHS-Nutrition 2004 used the Canadian Nutrient File as a food composition database when determining intakes (Health Canada, 2006). Although $>95 \%$ of foods in the Canadian Nutrient File have measured fibre values, the current laboratory methods used to analyze fibre in this database do not capture all types of fibre in food (Health Canada, 2012, 2015). As a result, the amount of fibre listed for each food item in the Canadian Nutrient File is also underestimated. Collectively, total fibre intake among Canadians is likely higher than what the 2004 CCHS-Nutrition has reported.

\section{Challenges to Using Adequate Intakes when Determining Nutrient Inadequacy in a Popula- tion}

One of the major limitations with using an AI, instead of an $\mathrm{EAR}$, is the inability to determine inadequacy of a nutrient within a given population. Due to the lack of requirement distributions among AI-based nutrients, a low prevalence of inadequacy is assumed if a population's average intake is at or above the AI; however, no conclusions can be drawn if the average intakes are below the AI (Institute of Medicine, 2006). In fact, the Institute of Medicine (2006) states that AIs likely overestimate any true requirement for the majority of individuals. Therefore, although CCHS-Nutrition 2004 shows that most Canadians have fibre intakes below the AI, it cannot be concluded that there is a high probability of fibre inadequacy among Canadians, resulting in ambiguity over whether Canadians' fibre intakes are truly of great concern.

Undoubtedly, fibre has been associated with many health benefits, making it important from a public health perspective to ensure Canadians are consuming adequate amounts of fibre. Although a high prevalence of fibre inadequacy cannot be assumed if the population's intake is below the AI, it makes it especially difficult to draw conclusions about the prevalence of fibre inadequacy if there are methodological issues to how the AIs were originally developed. As such, efforts to improve the fibre AIs such as selecting ageappropriate disease endpoints and using recent epidemiological data from Canada to estimate fibre and energy intakes would greatly improve our understanding of how fibre is associated with Canadians' health. Further, the inclusion of both dietary and functional fibre when determining fibre intakes, and using updated laboratory methods to measure all types of fibre in foods, would improve the assessment of fibre consumption among Canadians. Therefore, the onus is on researchers to improve the AIs for fibre and ensure that fibre is accurately measured at both the population and laboratory levels before any intervention strategies to improve fibre intakes are considered by Health Canada.

\section{References}

Benjamin, E. J., Muntner, P., Alonso, A., Bittencourt, M. S.,
Callaway, C. W., Carson, A. P., ... American Heart Association Council on Epidemiology and Prevention Statistics Committee and Stroke Statistics Subcommittee. (2019). Heart Disease and Stroke Statistics - 2019 Update: A Report From the American Heart Association. Circulation, 139, e1-e473. Retrieved from https://

www.ahajournals.org/doi/10.1161/

CIR.0000000000000659

Garriguet, D. (2018). Accounting for misreporting when comparing energy intake across time in Canada. Health Reports, 29(5), 3-12. Retrieved from https:// www150.statcan.gc.ca/n1/pub/82-003-x/2018005/ article/54965-eng.pdf

Health Canada. (2006). Canadian Community Health Survey Cycle 2.2, Nutrition (2004): A Guide to Accessing and Interpreting the Data. Ottawa, ON. Retrieved from https:// www.canada.ca/en/health-canada/services/food-nutrition/ food-nutrition-surveillance/health-nutrition-surveys/ canadian-community-health-survey-cchs/canadiancommunity-health-survey-cycle-2-2-nutrition-2004-guideaccessing-interpreting-data-health-canada-2006.html

Health Canada. (2012). Policy for Labelling and Advertising of Dietary Fibre-Containing Food Products. Ottawa, ON. Retrieved from https://www.canada.ca/en/health-canada/ services/food-nutrition/legislation-guidelines/policies/ policy-labelling-advertising-dietary-fibre-containing-foodproducts-2012.html

Health Canada. (2015). Canadian Nutrient File: Compilation of Canadian Food Composition Data. Ottawa, ON. Retrieved from https://www.canada.ca/en/health-canada/ services/food-nutrition/healthy-eating/nutrient-data/ canadian-nutrient-file-compilation-canadian-foodcomposition-data-users-guide.html

Health Canada, \& Statistics Canada. (2004). Canadian Community Health Survey, Cycle 2.2, Nutrition, 2004 - Nutrient Intakes from Food. Provincial, Regional and National Summary Data Tables, Volume 1. Ottawa, ON. Retrieved from https://www.canada.ca/content/dam/hc-sc/ migration/hc-sc/fn-an/alt_formats/hpfb-dgpsa/pdf/ surveill/cc_descri-eng.pdf

Hébert, J. R., Hurley, T. G., Steck, S. E., Miller, D. R., Tabung, F. K., Peterson, K. E., ... Frongillo, E. A. (2014). Considering the Value of Dietary Assessment Data in Informing Nutrition-Related Health Policy. Advances in Nutrition, 5 (4), 447-455. Retrieved from https://academic.oup.com/ advances/article/5/4/447/4568627

Institute of Medicine. (2005). Dietary Reference Intakes for Energy, Carbohydrate, Fiber, Fat, Fatty Acids, Cholesterol, Protein, and Amino Acids. Washington, DC: National Academy Press. Retrieved from default/files/fnic_uploads/energy_full_report.pdf 
Institute of Medicine. (2006). Dietary Reference Intakes: The Essential Guide to Nutrient Requirements. Washington, DC: National Academy Press. Retrieved from https:// www.nal.usda.gov/sites/default/files/fnic_uploads/

DRIEssentialGuideNutReq.pdf

Pietinen, P., Rimm, E. B., Korhonen, P., Hartman, A. M., Willett, W. C., Albanes, D., \& Virtamo, J. (1996). Intake of Dietary Fiber and Risk of Coronary Heart Disease in a Cohort of Finnish Men. The Alpha-Tocopherol, Beta-Carotene Cancer Prevention Study. Circulation, 94(11), 2720-2727. Retrieved from https://www.ahajournals.org/doi/

full/10.1161/o1.CIR.94.11.2720

Rimm, E. B., Ascherio, A., Gionvannucci, E., Spiegelman, D., Stampfer, M. J., \& Willet, W. C. (1996). Vegetable, Fruit, and Cereal Fiber Intake and Risk of Coronary Heart Disease Among Men. JAMA, 275(6), 447-451. Retrieved from https://jamanetwork.com/journals/jama/articleabstract $/ 396216$

The ATBC Cancer Prevention Study Group. (1994). The Alpha-Tocopherol, Beta-Carotene Lung Cancer Prevention Study: Design, Methods, Participant Characteristics, and Compliance. Annals of Epidemiology, 4(1), 1-10. Retrieved from https://www.sciencedirect.com/science/article/ pii/1047279794900361?via\%3Dihub

U.S. Department of Agriculture, Agricultural Research Service, Beltsville Human Nutrition Research Center, \& Food Surveys Research Group. (2016). Continuing Survey of Food Intakes by Individuals 1994-96, 1998 and Diet and Health Knowledge Survey 1994-96. Beltsville, MD. Retrieved from https://www.ars.usda.gov/northeast-area/ beltsville-md-bhnrc/beltsville-human-nutrition-researchcenter/food-surveys-research-group/docs/csfii-1994-19961998-and-dhks-1994-1996/

Wolk, A., Manson, J. E., Stampfer, M. J., Colditz, G. A., Hu, F. B., Speizer, F. E., ... Willet, W. C. (1999). Long-term Intake of Dietary Fiber and Decreased Risk of Coronary Heart Disease Among Women. JAMA, 281(21), 1998-2004. Retrieved from https://jamanetwork.com/journals/jama/ fullarticle/190211 